\title{
Modeling the performance of an integrated battery and electrolyser system
}

Andrea Mangel Raventos ${ }^{[a]}$, Gerard J. Kluivers ${ }^{[a]}$, Willem Haverkort ${ }^{[b]}$, Wiebren de Jong ${ }^{[a]}$, Fokko M. Mulder ${ }^{[c]}$, Ruud Kortlever ${ }^{[a]^{*}}$

[a] Large-Scale Energy Storage, Department of Process \& Energy, Faculty of Mechanical,

Maritime and Materials Engineering, Delft University of Technology, Leeghwaterstraat 39,

2628 CB Delft, The Netherlands

*Email: r.kortlever@tudelft.nl

[b] Department of Process \& Energy, Faculty of Mechanical, Maritime and Materials

Engineering, Delft University of Technology, Leeghwaterstraat 39, 2628 CB Delft, The

Netherlands

[c] Materials for Energy Conversion and Storage, Department of Chemical Engineering,

Faculty of Applied Science, Delft University of Technology, Van der Maasweg 9, 2629 HZ

Delft, The Netherlands 


\section{Table of Contents}

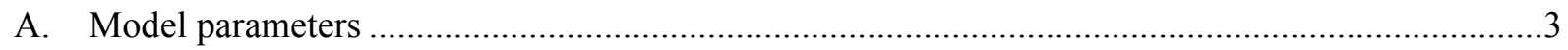

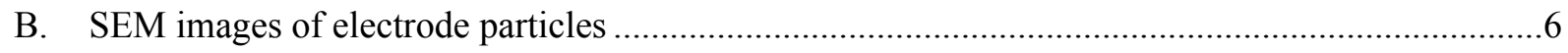

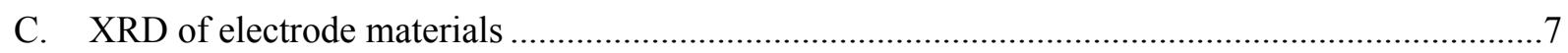

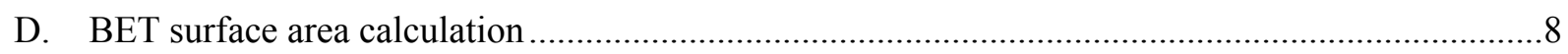

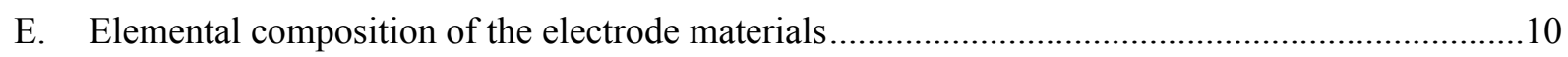

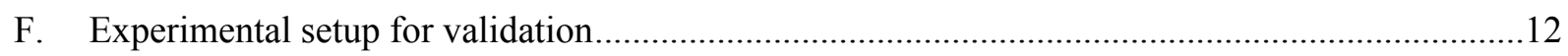

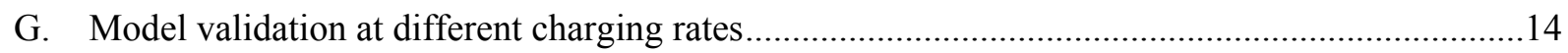

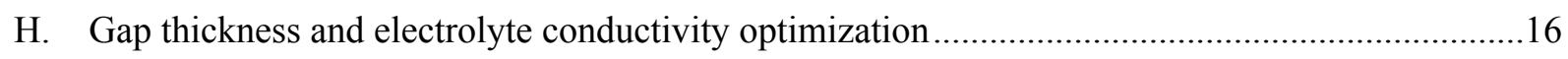

I. Electrolyte concentration profiles calculated with the model......................................................19

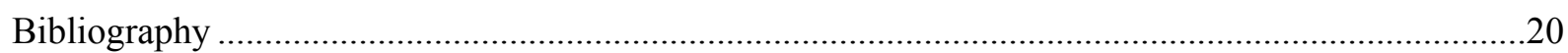




\section{A. Model parameters}

The kinetic and thermodynamic parameters that were used in the simulations are detailed in this section. Further information on parameters that were measured experimentally can be found in the following sections.

The kinetic and thermodynamic parameters of the $\mathrm{Ni}(\mathrm{OH})_{2}$ electrode are from Paxton and Newman ${ }^{1}$ and are presented in Table S.1. Sinha ${ }^{2}$ measured these kinetic parameters in different electrolyte concentrations. Paxton and Newman ${ }^{1}$ took this data and made a fit to the general Butler-Volmer equation to determine the average values. These average values were used in the presented model.

Table S.1. Kinetic parameters for the battery charging reactions for $\mathrm{Ni}(\mathrm{OH})_{2}$ from ${ }^{1}$.

\begin{tabular}{ll}
\hline $\mathrm{i}_{0}$ & $1.04 \times 10^{-4} \mathrm{~A} / \mathrm{cm}^{2}$ \\
$\mathrm{a}_{\mathrm{a}}$ & 0.13 \\
$\mathrm{a}_{\mathrm{c}}$ & 0.074 \\
\hline
\end{tabular}

The equilibrium potential of $\mathrm{Ni}(\mathrm{OH})_{2}$ is taken as dependent on the state of charge of the electrode. Conway and Gilead have shown that the nickel electrode is a mixed potential electrode due to the effect of OER at higher states of charge ${ }^{3}$. 


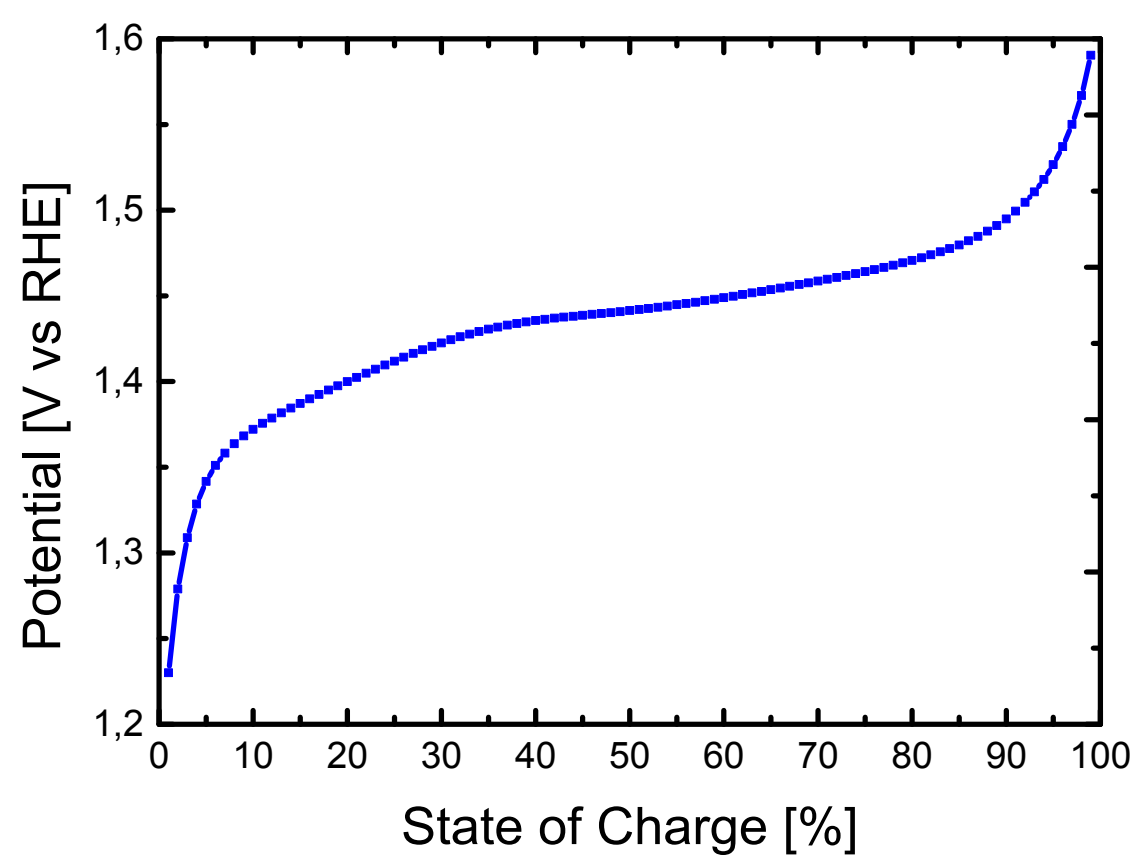

Figure S.1. Standard electrode potential of the nickel hydroxide positive electrode dependent on state of charge of the battery ${ }^{1}$.

The iron electrode, on the other hand is considered to have a constant potential throughout the charging process and the material consists of two different phases with a standard electrode potential of .- $0.164 \mathrm{~V}$ vs RHE. The kinetic parameters of the iron electrode have been used to calculate the onset potential of the integrated battery and electrolyser system, with an exchange current density of $0.003 \mathrm{~A} / \mathrm{m}^{2}$ and anodic and cathode coefficients of 0.5 .

The kinetic parameters of the gas production reactions are presented in Table S.2.

Table S.2 Kinetic parameters for the gas production reaction (OER and HER) on both electrodes.

\begin{tabular}{ll}
\hline OER & HER \\
\hline
\end{tabular}




\begin{tabular}{ccc}
\hline $\mathrm{E}^{0}$ & $1.23 \mathrm{~V}$ vs RHE & $0 \mathrm{~V}$ vs RHE \\
$\mathrm{i}_{0}$ & $0.00005 \mathrm{~A} / \mathrm{m}^{2}$ & $0.0003 \mathrm{~A} / \mathrm{m}^{2}$ \\
$\mathrm{a}_{\mathrm{a}}$ & 0.45 & 0.5 \\
$\mathrm{a}_{\mathrm{c}}$ & 0.5 & 0.5 \\
\hline
\end{tabular}

Table S.3 Parameter values used- base case scenario.

\begin{tabular}{ccc}
\hline Parameter & Value & Units \\
\hline Nickel electrode thickness & 4 & {$[\mathrm{~mm}]$} \\
Iron electrode thickness & 3 & {$[\mathrm{~mm}]$} \\
Gap thickness & 3 & {$[\mathrm{~mm}]$} \\
Membrane thickness & 0.5 & {$[\mathrm{~mm}]$} \\
Membrane porosity & 0.5 & \\
Electrode porosity & 0.5 & \\
Temperature & 293.15 & {$[\mathrm{~K}]$} \\
Electrolyte concentration & 5 & {$[\mathrm{~mol} / \mathrm{L}]$} \\
Electrolyte diffusion coefficient & $3.75 \times 10-9$ & {$[\mathrm{~m} 2 / \mathrm{s}]$} \\
\hline
\end{tabular}




\section{B. SEM images of electrode particles}

SEM imaging and EDX were performed using a JEOL JSM 6500F microscope.

With regards to the nickel material used in the positive electrode, SEM images are presented in

Figure S.2(a). As can be seen in this Figure, the particle size distribution is quite broad. Using

EDX, the large particles are identified as graphitic carbon. The graphite particles are approximately 5 times larger than the active material nickel particles. Nickel particle size ranges from $30 \square \mathrm{m}$ to only a few $\square \mathrm{m}$. The average particle size for the nickel material is $2.3 \mu \mathrm{m}$.

For the iron electrode presented in Figure S2(b), it can be observed that the iron particle size distribution is more narrow. The larger particles in the image are graphitic carbon, identified by EDX. The iron particles are more similar in size, and also smaller than the nickel hydroxide particles in the nickel electrode. The average iron particle size is $2 \mu \mathrm{m}$.

(a)

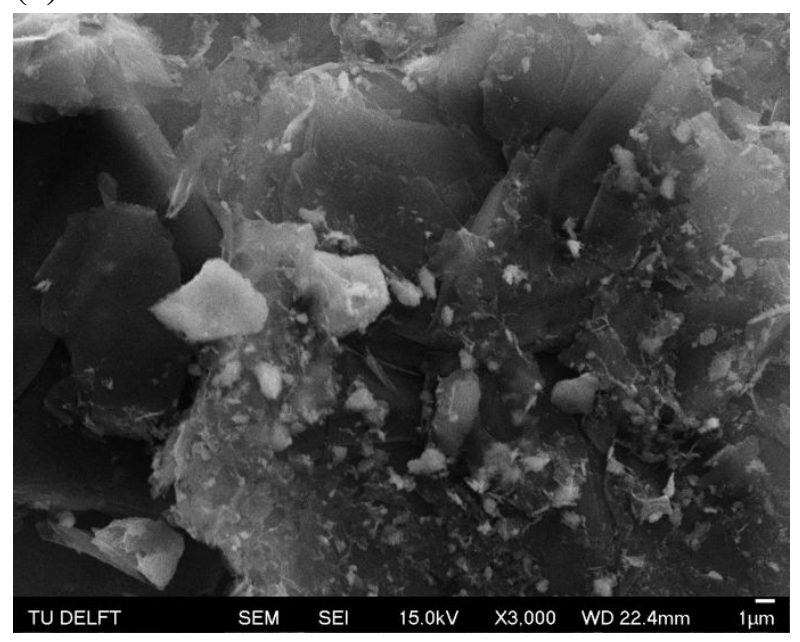

(b)

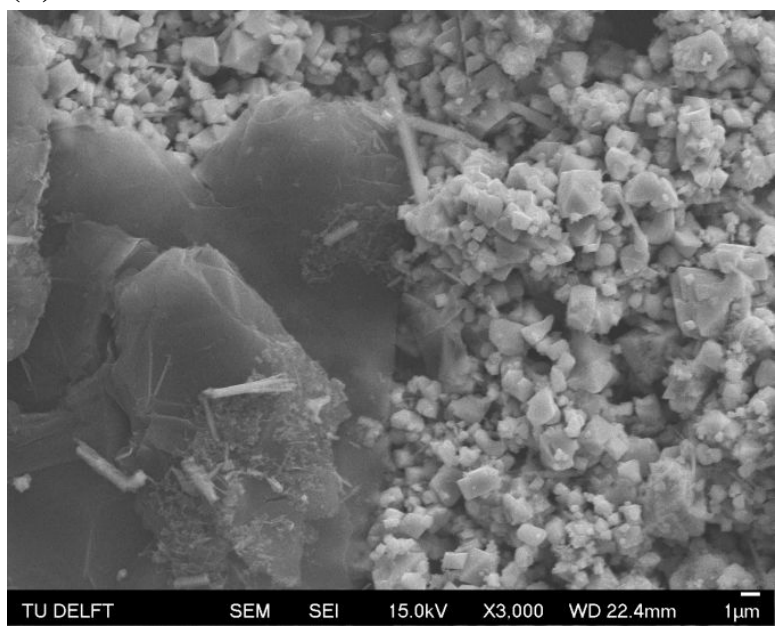


Figure S.2. SEM-SEI images of the active electrode material. (a) Nickel positive electrode material and (b) Iron negative electrode material. 


\section{XRD of electrode materials}

XRD analysis was done using a Bruker D2 PHASER. The results were analyzed using the

DIFFRAC SUITE software package.

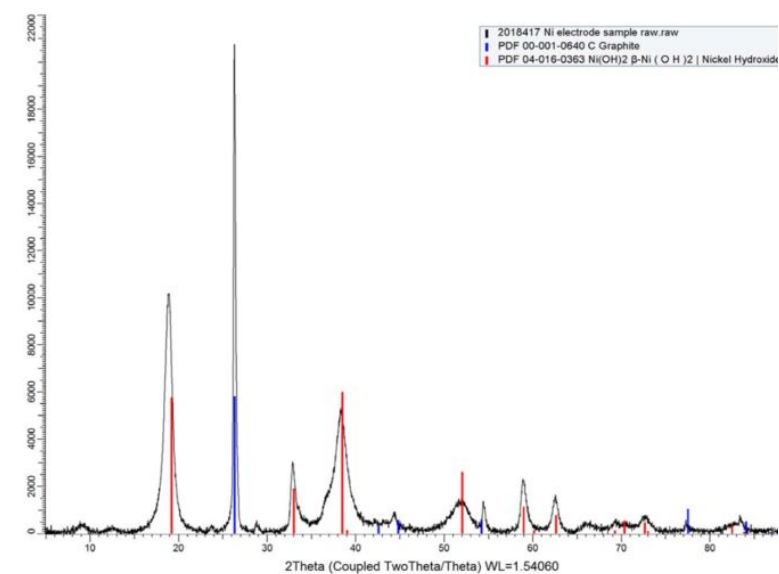

(a)

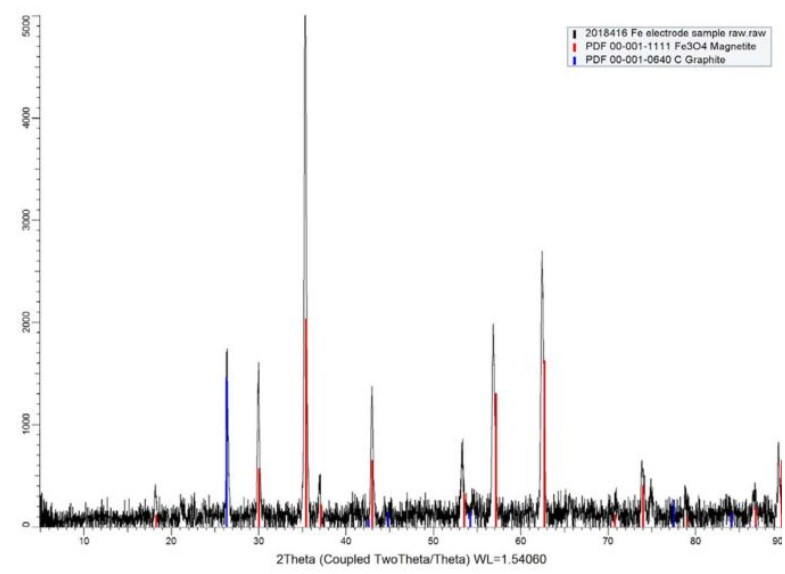

(b)

Figure S.3. XRD analysis of the active electrode material. (a) Nickel positive electrode material, where the red lines indicate the peaks associated with $\beta-\mathrm{Ni}(\mathrm{OH})_{2}$ and the blue lines are related to graphitic carbon peaks and (b) Iron negative electrode material, where the red lines indicate peaks associated with magnetite $\mathrm{Fe}_{3} \mathrm{O}_{4}$ and the blue lines are again related to the graphitic carbon content.

This confirms the main composition of the Nickel positive electrode material as graphite and $\beta-\mathrm{Ni}(\mathrm{OH})_{2}$. The XRD diffraction pattern of the iron active material is presented in Figure S.3.

This confirms that there is also graphite present in the sample and the iron material is present in magnetite $\left(\mathrm{Fe}_{3} \mathrm{O}_{4}\right)$ form. This is due to a self-discharging mechanism because of the stability of the material in air. 


\section{BET surface area calculation}

Brunauer-Emmett-Teller (BET) theory serves as the theoretical basis for a standard specific

surface area measurement technique. The analysis uses multilayer adsorption with probing gases that do not chemically react with the material surfaces to quantify the specific surface area. Nitrogen was used, and therefore the analysis is conducted at the boiling temperature of N2. A Gemini VII 2390p analyzer was used to perform this technique. The surface area was measured via BET analysis, and the adsorption isotherm is presented in Figure S.4. This is a straight line as expected.

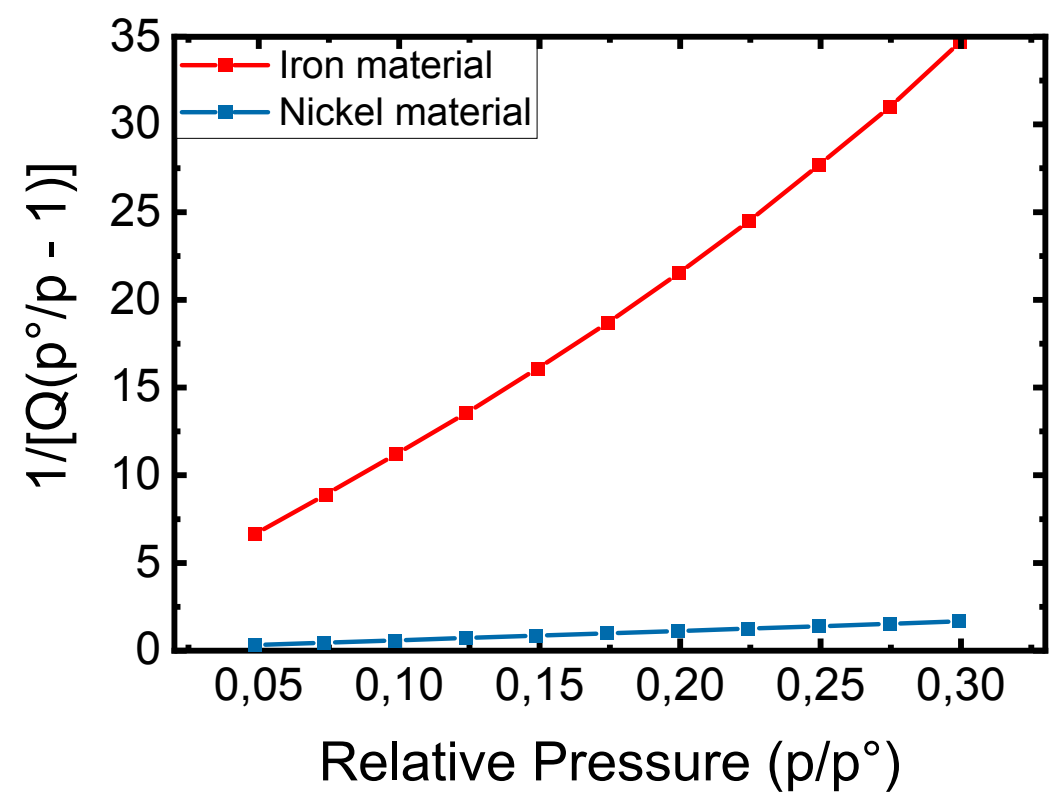

Figure S.4. BET surface area plot for the nickel and iron materials. 
For the nickel electrode material, the specific surface area obtained is $17.99 \mathrm{~m}^{2} / \mathrm{g}$. The BET surface area measured is approximately 50 times larger than the area calculated for a packed bed of spherical particles with a diameter equal to the average particle.

For the iron electrode material, the specific surface area obtained is $0.88 \mathrm{~m}^{2} / \mathrm{g}$. The BET area calculated is less than two times as large as that of the theoretical calculation. By this measurement, the iron active material is less porous than the nickel material. 


\section{E. Elemental composition of the electrode materials}

Inductively Coupled Plasma Optical Emission Spectroscopy (ICP-OES) was used as an analytical technique to determine the elemental composition of a sample. Samples are dissolved in $\mathrm{H}_{2} \mathrm{O}_{2}$ and digested close to boiling point for 4 hours. Then the samples were diluted in $3 \mathrm{v} \%$ $\mathrm{HNO}_{3}$. This liquid is injected in the form of aerosol into an argon plasma. The plasma excites the atoms and ions, causing them to emit electromagnetic radiation at a particular wavelength characteristic to a particular element. The intensity of the emission is proportional to the concentration of the element.

The elemental composition of the active material inside the pockets was obtained by ICP-OES analysis. The electrode pockets were opened and the compacted material was extracted. The results are presented in Table S.4.

Table S.4. ICP-OES results for the nickel and iron electrode sample

\begin{tabular}{ccc}
\hline Element & $\begin{array}{c}\text { Nickel Electrode } \\
\text { Mass percentage } \\
{[\%]}\end{array}$ & $\begin{array}{c}\text { Iron Electrode } \\
\text { Mass percentage } \\
{[\%]}\end{array}$ \\
\hline $\mathrm{Fe}$ & 0.100 & 98.193 \\
$\mathrm{Ni}$ & 93.253 & 0.252 \\
$\mathrm{Al}$ & 0.012 & 0.032 \\
$\mathrm{SO}_{4}{ }^{2-}$ & 0.146 & 0.191 \\
$\mathrm{Li}$ & 4.636 & 0.017 \\
$\mathrm{Na}$ & 4.636 & 1.094
\end{tabular}




\begin{tabular}{ccc}
$\mathrm{Zn}$ & 0.037 & 0.056 \\
$\mathrm{Si}$ & 0.062 & 0.065 \\
$\mathrm{PO}_{4}^{2-}$ & 0.102 & 0.046 \\
$\mathrm{Cd}$ & 0.013 & 0.013 \\
$\mathrm{Sn}$ & 0.013 & 0.038 \\
$\mathrm{Ca}$ & 0.022 & - \\
$\mathrm{Ti}$ & - & 0.004 \\
$\mathrm{Ba}$ & - & 1.447 \\
\hline
\end{tabular}

Due to the dilution process, carbon is not included in ICP-OES analysis results. The nickel hydroxide positive electrode, as expected, is composed mainly of nickel. Some iron is also present in the nickel electrode. This can be due to crossover during charging and discharging cycles because of the solubility of iron in $\mathrm{KOH}$. This is expected as the sediment found in the bottom of the battery has a high mass percentage of iron. The iron crossover can decrease the overpotential for oxygen evolution in $\mathrm{NiOOH}$ materials ${ }^{4}$. Lithium and sodium can be present because of the use of $\mathrm{LiOH}$ and $\mathrm{NaOH}$ in the $\mathrm{KOH}$ electrolyte during previous battery cycles. The role of different cations in the nickel hydroxide structure is not yet well understood. $\mathrm{Zn}$, Cd, and Sn are typical HER inhibitors, and are believed to have been added to the iron electrode to avoid the secondary reaction. Cadmium and cobalt are used as additives to the nickel hydroxide electrode to increase the conductivity and the oxygen evolution potential 


\section{F. Experimental setup for validation}

The experimental setup used for validation tests is composed of a commercial battery setup. A

schematic representation is presented in Figure S.5(a).

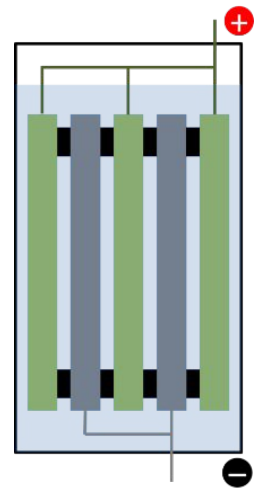

(a)

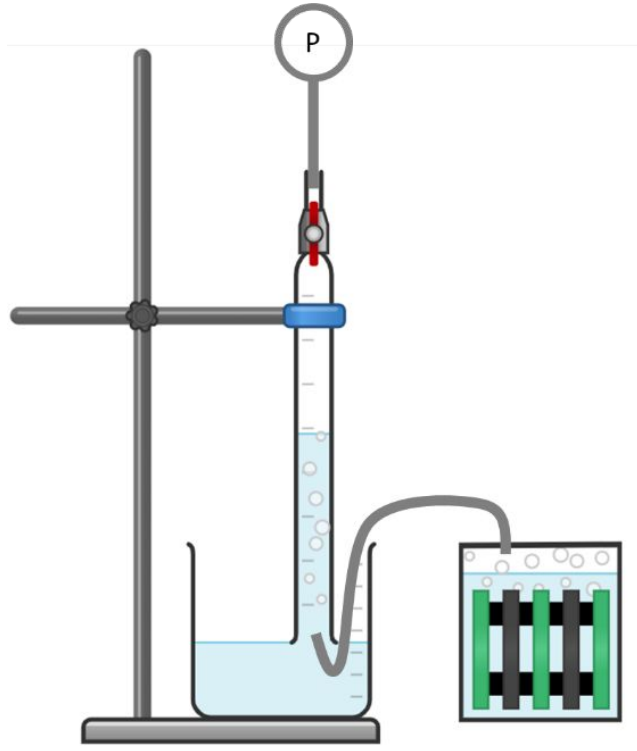

(b)

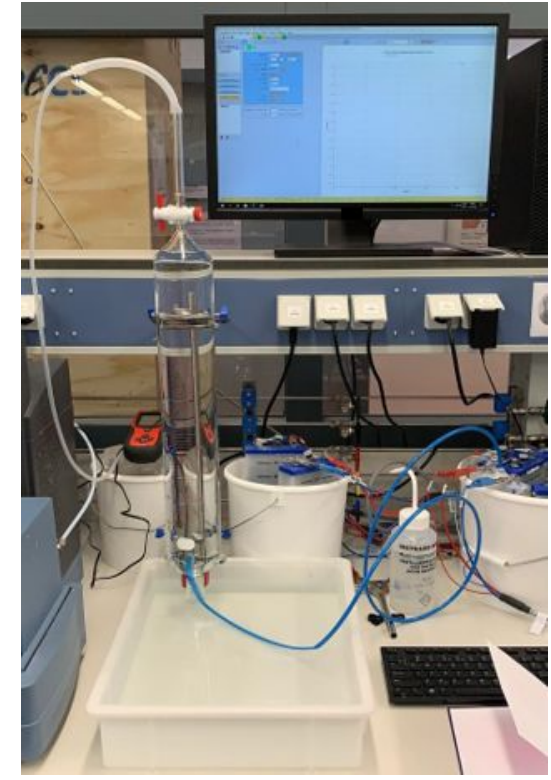

(c)

Figure S.5. (a) Commercial battery setup including: 3 positive nickel electrodes (in green), 2 negative iron electrodes (in grey), alkaline electrolyte and rubber separators (black) to avoid short-circuits. The cell is encased in a plastic casing with metal connectors for the positive and negative electrodes. (b) Schematic of the reverse burette experimental setup to measure the total gas production (c) Experimental setup used to measure total gas production.

A schematic representation of the experimental setup used to measure gas production is presented in Figure S.5(b) and (c). Before the charging cycle the system was flushed with Argon gas. After charging the battery, samples of the collected gas were taken and the composition determined in a microGC. The microGC model is Varian $\mu$-GC CP4900, with a $1 \mathrm{~m} \mathrm{CP-COX}$ column and a TCD detector. The carrier gas is Argon. 
The volume of gas produced was measured every 15 minutes. The total gas production results are shown in Figure S.6. The volumetric percentage of hydrogen in the gas collected is $60 \%$ according to the measurement with a microGC.

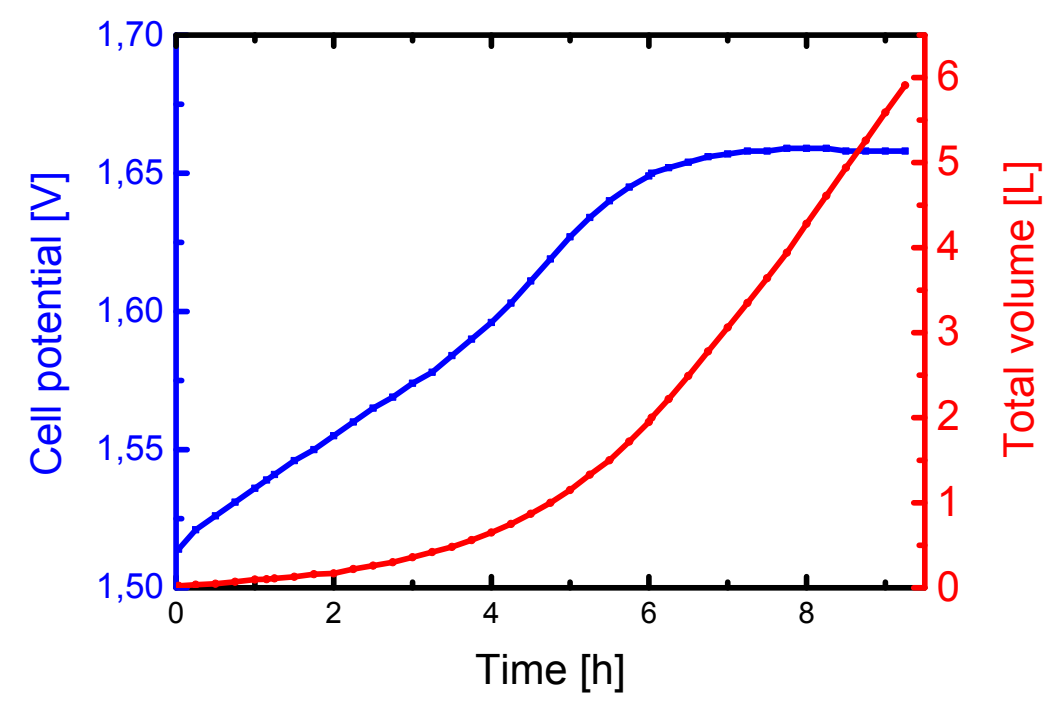

Figure S.6. Cell potential vs. elapsed time during a charging gas production cycle (blue) and total gas production measured by water displacement (red).

During the first 6 hours of the measurement, when the cell potential is still increasing the battery is charging. Therefore, the catalysts for HER/OER are still being produced inside the battery electrodes. After this time, the battolyser functions in electrolysis mode and the total volume produced is expected to be linear, as shown in the measurement above.

The relationship between total gas produced versus elapsed time is only linear when the battery is fully charged and the amount of gas produced is constant. Therefore, before the time when 
the electrodes are fully charged the relationship is not expected to be linear, as the catalysts for HER/OER are being produced on both electrodes.

\section{G. Model validation at different charging rates}

To further validate the model results, different simulations were run at different current densities. These are compared to experimental measurements at the same charge/discharge currents.

These results are presented below for inserted charge of 1.5 A, 2 A, and 4 A. Discharge was performed at the same current, but in the opposite direction.

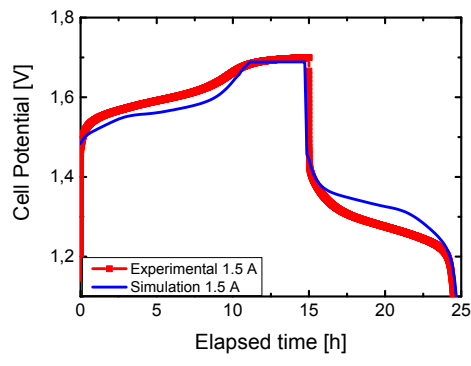

(a)

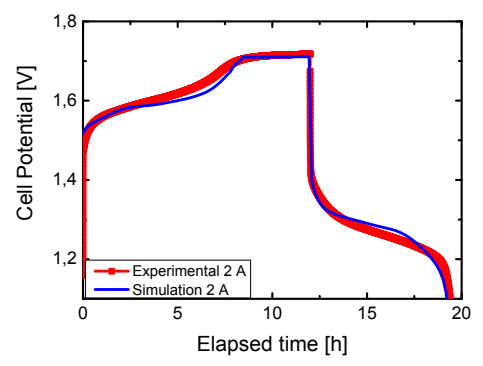

(b)

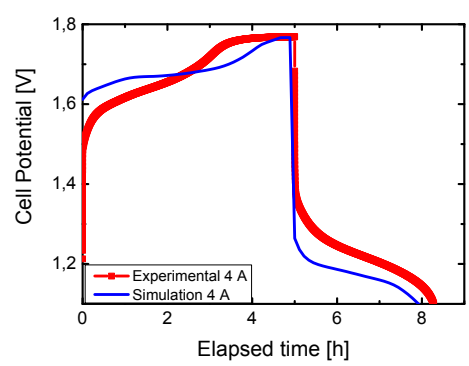

(c) 
Figure S.7. Cell potential vs. elapsed time during a charging gas production cycle at (a) $1.5 \mathrm{~A}$ (b) $2 \mathrm{~A}$ and (c) $4 \mathrm{~A}$.

Generally speaking, the onset potential of the battery charging is fairly constant in experiments but strongly dependent on current density in the simulations. The parameters were fit to the $2 \mathrm{~A}$ current as this is the rated current for the batteries. Further optimization simulations were run at the equivalent for $2 \mathrm{~A}$ in a 2 electrode system since this is the rated current recommended by the battery manufacturer. Validation measurements at higher current densities are carried out only to determine whether the variations are significant.

The onset potential of HER/OER is accurate on all 3 experimental sets, and comparable to the simulation results. Furthermore, the battery capacity is estimated well for all 3 current values. The discharging potential is overestimated for the 1.5 A measurement and underestimated for the $4 \mathrm{~A}$ results. This, together with the overestimation of the onset potential of the battery charging leads us to think that the ohmic drop might be higher in the model than in the experimental cell. As you increase the current the ohmic losses would increase disproportionately, resulting in a mismatch of potential. This can be due to the assumption that parameters such as the porosity and surface area are considered not to scale with SoC. 
However, all 3 results are adequate to proceed with the optimization scenarios, as the simulated gas production values and the efficiency results at the rated charging current are accurate and comparable to the experimental results. 


\section{H. Gap thickness and electrolyte conductivity optimization}

\section{Gap thickness}

The gap thickness was multiplied by a scaling factor to study the effect on battery and total efficiency In Figure S.8(a) it can be seen how battery efficiency and total efficiency increase until the gap thickness is double the starting dimension of $3 \mathrm{~mm}$ on each side of the membrane.

Because the products of the secondary reactions, namely $\mathrm{H}_{2}$ and $\mathrm{O}_{2}$ are produced in a gaseous state, the effect of product accumulation should be further studied. Furthermore, bubble accumulation and its effect on fluid dynamics will play a role in determining the optimal gap thickness for the battolyser.

Ohmic losses increase as the gap thickness increases, however this will also allow for bubble removal and more turbulent flow due to bubble movement. Since battery capacity and hydrogen production does not increase considerably, $3 \mathrm{~mm}$ gap thickness is chosen, but must be further studied to determine if a larger gap is beneficial. Barton et al. discuss the effect of increasing the gap thickness on the total ohmic losses in a similar battolyser cell ${ }^{5}$. 


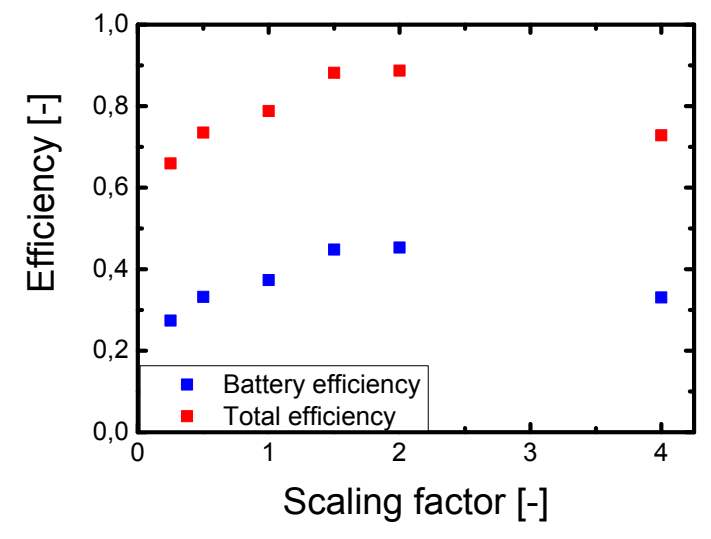

(a)

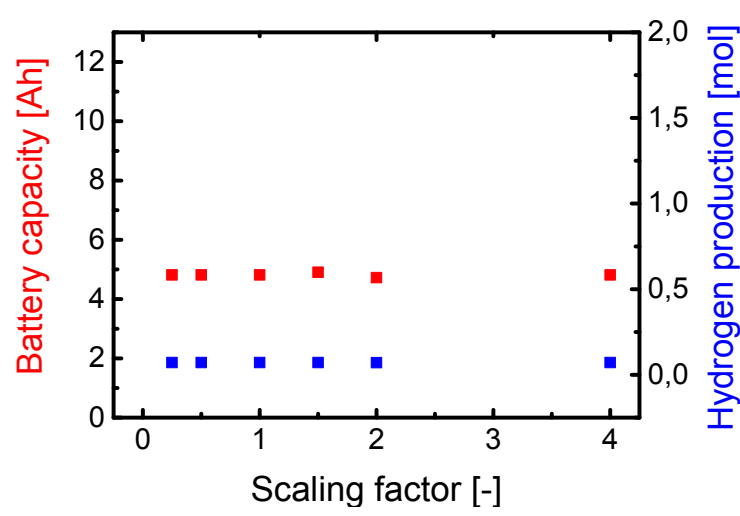

(b)

Figure S.8 (a) Battery and total integrated efficiency with respect to a scaling factor that multiplies the gap thickness (b) Battery capacity and total hydrogen production vs. gap thickness.

Ohmic losses are not dominating in this application because of low currents and high $\mathrm{KOH}$ conductivity. Therefore, the gap thickness is not the dominating contributor losses. Both the optimization of the electrolyte conductivity and the gap thickness were run to determine if they were important in further designs of the battolyser. Through these simulations it was determined that they were not as significant as other parameters

\section{Electrolyte conductivity}

The electrolyte conductivity was also optimized. Figure S.9(a) shows the small increase in efficiency at half the value of the conductivity of the electrolyte. Since the increase is small, more information was looked at for this parameter optimization. 


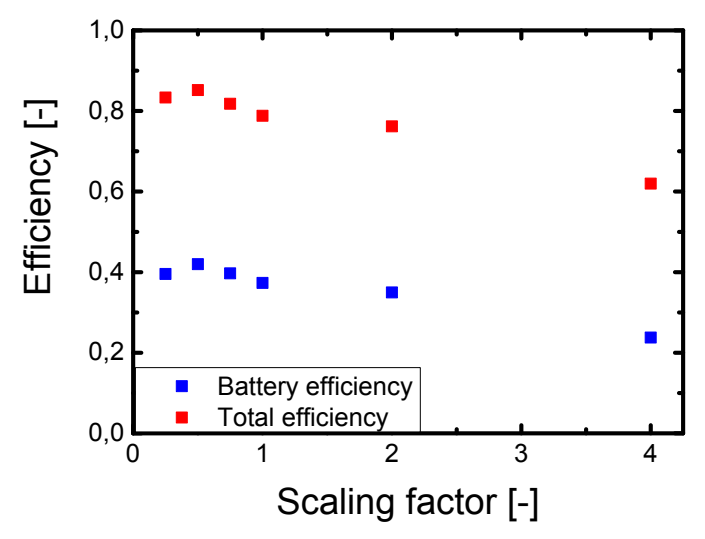

(a)

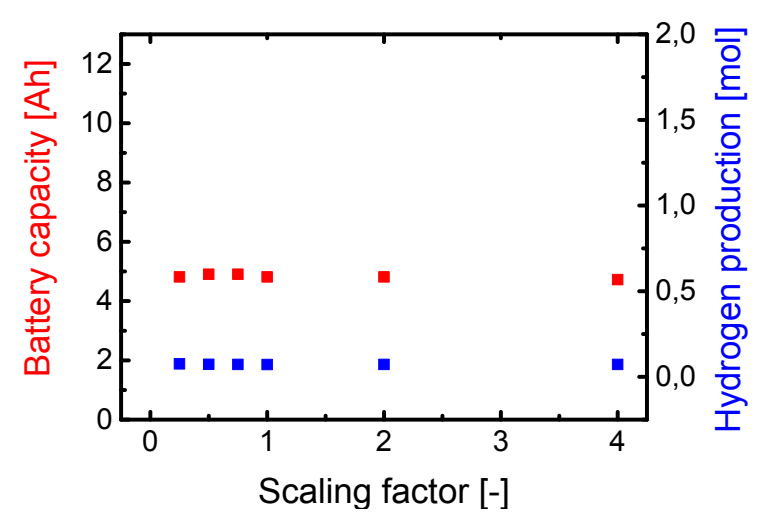

(b)

Figure S.9. (a) Battery and total integrated efficiency with respect to the electrolyte conductivity (b) Battery capacity and total hydrogen production vs. electrolyte conductivity.

According to Gilliam et al. at room temperature, conductivity of $\mathrm{KOH}$ reaches a plateau value as the concentration increases. To consider cost effects of high electrolyte concentrations, for further optimization scenarios, $5 \mathrm{M} \mathrm{KOH}$ is used $^{6}$. However, this should be studied further as the increase in efficiency at lower concentrations of electrolyte is not fully understood.

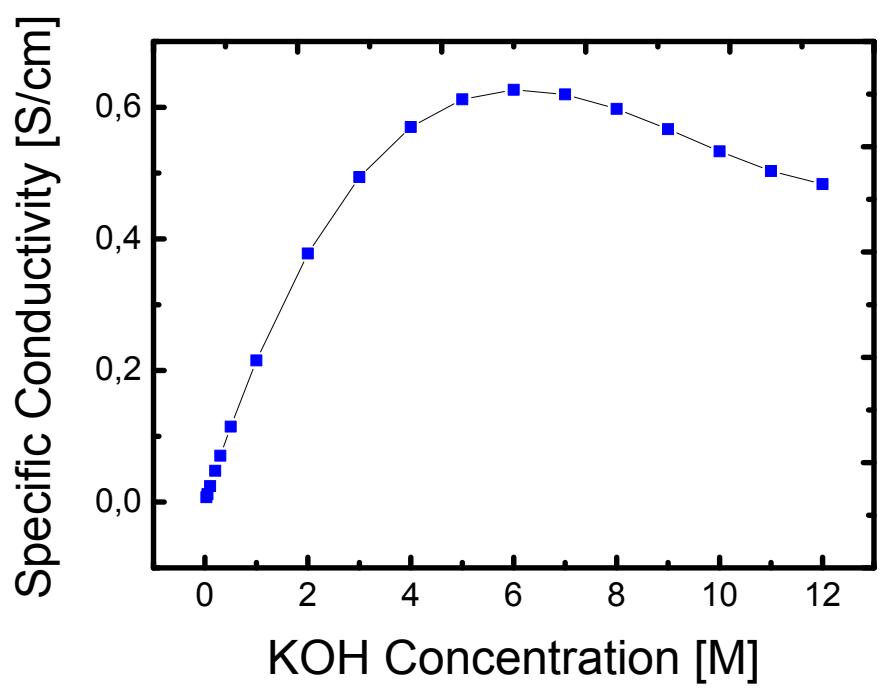

Figure S.10. Specific conductivity of $\mathrm{KOH}$ with respect to concentration at $20^{\circ} \mathrm{C}$. Data from Gilliam et al. ${ }^{6}$ 


\section{Electrolyte concentration profiles calculated with the model}

The concentration profiles of $\mathrm{OH}$ - concentration through the $\mathrm{x}$-coordinate of the cell are presented in this section.

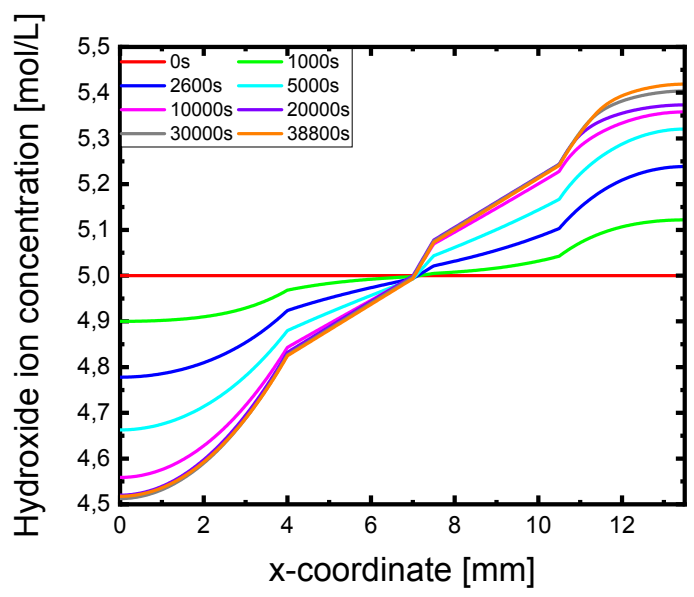

(a)

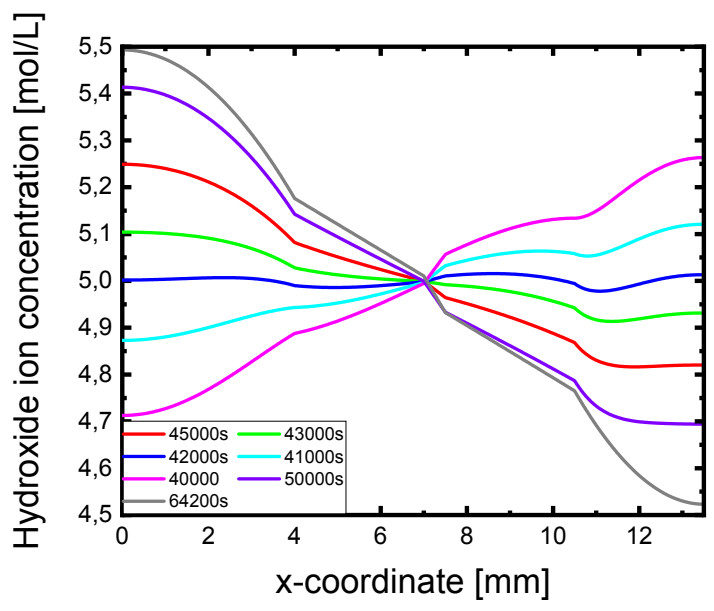

(b)

Figure S.11. (a) Hydroxide concentration profiles in the x-coordinate during charge and electrolysis (b) Hydroxide concentration profiles in the $\mathrm{x}$-coordinate during discharge. 


\section{Bibliography}

(1) Paxton, B.; Polymers, M. B. A.; Newman, J. Modeling of Nickel / Metal Hydride Batteries. J. Electrochem. Soc. 1997, 144 (11), 3818-3831.

(2) Sinha, S.; Humphrey, B. D.; Bocarsly, A. B. Reaction of Nickel Electrode Surfaces with Anionic Metal-Cyanide Complexes: Formation of Precipitated Surfaces. Inorg. Chem. 1984, 23 (2), 203212. https://doi.org/10.1021/ic00170a018.

(3) Conway, B. E.; Gileadi, E. Electrochemistry of the Nickel Oxide Electrode: Part IV. Electrochemical Kinetic Studies of Reversible Potentials As a Function of Degree of Oxidation. Can. J. Chem. 1962, 40 (10), 1933-1942. https://doi.org/10.1139/v62-297.

(4) Garcia, A. C.; Touzalin, T.; Nieuwland, C.; Perini, N.; Koper, and M. T. M. Enhancement of Oxygen Evolution Activity of $\mathrm{NiOOH}$ by Electrolyte Alkali Cations. Angew. Chemie 2019, 58 (37), 12999-13003. https://doi.org/10.1002/anie.201905501.

(5) Barton, J. P.; Gammon, R. J. L.; Rahil, A. Characterisation of a Nickel-Iron Battolyser, an Integrated Battery and Electrolyser. Front. energy Res. 2020, 8, 509052.

(6) Gilliam, R. J.; Graydon, J. W.; Kirk, D. W.; Thorpe, S. J. A Review of Specific Conductivities of Potassium Hydroxide Solutions for Various Concentrations and Temperatures. Int. J. Hydrogen Energy 2007, 32 (3), 359-364. https://doi.org/10.1016/j.ijhydene.2006.10.062. 